\title{
Perceptions of precautionary labelling among parents of children with food allergy and anaphylaxis
}

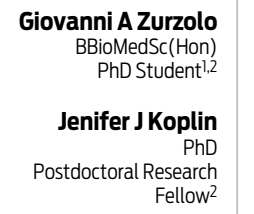

Michael L Mathai

Associate Professor, Col of Health and Biomedicine ${ }^{2}$

Mimi K L Tang PhD, FRACP Director, Department of Allergy and Immunology ${ }^{3}$

Katrina J Allen PhD, FRACP Director, Population Health ${ }^{2}$

1 Victoria University Melbourne, VIC

2 Murdoch Childrens Research Institute, Melbourne, VIC.

3 Royal Children's Hospital, Melbourne, VIC

katie.allen@rch.org.au

MJA 2013; 198: 621-623 doi: 10.5694/mjal2.11669
$\mathrm{P}$ recautionary labelling for food allergens such as "may contain traces of" are now present on more than half of all packaged processed foods in Australian supermarkets. ${ }^{1}$ Recent European and United States studies have shown that this high prevalence of precautionary labelling as well as consumers' understanding that these statements are voluntary may have led to consumers not heeding precautionary statements. This might expose foodallergic consumers to the risk of allergen contamination, which may lead to life-threatening reactions such as anaphylaxis. ${ }^{2,3}$

The Australian manufacturing industry has undertaken to develop a new standard known as VITAL (voluntary incidental trace allergen labelling), to help improve standards for declaring the presence of allergens within foods. In 2007, a new precautionary statement "may be present" was introduced. The VITAL process has attracted international interest, but, to date, the "may be present" statement is rarely used. . $^{1,4}$

In this study, we aimed to gain an understanding of the behaviour, perceptions and opinions of parents about precautionary labelling, stratified by whether or not their food-allergic child had a history of anaphylaxis. We also aimed to understand consumers' perceptions of the "may be present" statement advocated by VITAL.

\section{Methods}

Participants were recruited in the Department of Allergy and Immunology at the Royal Children's Hospital, Melbourne, from 1 August to 31 October 2011. The parents (one only) of a consecutive series of children who had an appointment for a skin-prick test to investigate possible or established food allergy were asked to complete a self-administered questionnaire.

\section{Abstract}

Objective: To examine the behaviour and perception of parents of food-allergic children with and without a history of anaphylaxis in relation to precautionary labelling on packaged foods and to understand consumers' perception of the "may be present" statement advocated by VITAL (voluntary incidental trace allergen labelling).

Design, setting and participants: Questionnaire-based study of parents of a consecutive series of 497 children who attended the Department of Allergy and Immunology at the Royal Children's Hospital, Melbourne, from 1 August to 31 October 2011, of whom 293 met our criteria of having an existing medically diagnosed food allergy, and of whom 246 had enough information provided to be included in our analysis.

Main outcome measures: Parents' responses about their behaviour and perceptions relating to precautionary food labels, and a comparison between parents of children with a past history of anaphylaxis and those with a past history of mild to moderate IgE allergic reactions.

Results: Avoidance of foods with precautionary labels differed depending on the wording of the precautionary statement, with 74 parents (65\%) ignoring the statement "made in the same factory" compared with 24 (22\%) for "may be present". There was no evidence of a difference in participants' behaviour or perceptions depending on whether or not their child had a history of anaphylaxis.

Conclusions: Consumers are choosing a gradient level of risk based on the wording of the precautionary statements and appear to be complacent about precautionary labelling. Many statements are now being disregarded by a sizeable proportion of parents of food-allergic children, including those caring for children with a past history of anaphylaxis. This may be due to inadequacies in food labelling legislation. Policies that promote greater clarity and consistent use of precautionary statements may help to deal with this complacency.

All analyses were restricted to children with current medically diagnosed food allergy, and grouped based on the following:

- children with a past history of anaphylaxis, defined as a past history of respiratory or cardiovascular compromise in the setting of an acute allergic reaction; ${ }^{5}$ and

- children with a past history of mild to moderate IgE-mediated reactions, defined as immediate reactions involving the skin or gastrointestinal system (eg, vomiting, abdominal pain, diarrhoea, hives, and swelling of the eyes, lips or face) without involvement of the airway or circulatory systems.

We compared responses between the parents of children with and without a history of anaphylaxis using Pearson $\chi^{2}$ tests.

This study was approved by the Royal Children's Hospital Human Research Ethics Committee ( $\mathrm{RCH}$ HREC 31140A).

\section{Results}

The parents of 535 children were approached, and those of 497 children (93\%) agreed to participate. Two-thirds of the children (66\%) were boys and $84 \%$ were aged under 10 years. Food allergy had been medically diagnosed in 293 (59\%) of these children. The most common food allergies were to peanut (152 children; 52\%), egg (142; 48\%), tree nuts (112; 38\%) and milk (81; 28\%). Of the 293 children with food allergy, 246 (84\%) had sufficient information provided to allow past reactions to be classified as either a past history of anaphylaxis (113 children) or a past history of mild to moderate IgEmediated reactions (133 children). Among children with a history of anaphylaxis, the parents of 84 (74\%) reported that their child had been treated at an emergency department or been hospitalised. 
1 Behaviour relating to food labels among parents of food-allergic children with a history of anaphylaxis (113) and with a history of mild to moderate IgE-mediated reactions (133)

Question and possible responses

Anaphylaxis

Mild-moderate

reactions

If your child has a specific food allergy (eg, peanuts) do you intentionally remove food products containing the specific food from the house?

$\begin{array}{lcc}\text { No } & 39(35 \%) & 65(49 \%) \\ \text { Not sure } & 1(1 \%) & 3(2 \%) \\ \text { Yes } & 73(55 \%) & 64(48 \%) \\ \text { When you buy a food product which part of the label do you check for an allergen? } & 27(24 \%) & 32(25 \%) \\ \text { Ingredients only } & 1(1 \%) & 1(2 \%) \\ \text { Precautionary information only } & 82(73 \%) & 95(74 \%) \\ \text { Both } & 2(2 \%) & 1(1 \%)\end{array}$

Would you give your child a food if the food he or she was allergic to was listed in the precautionary labelling section?

No

$64(58 \%) \quad 81(62 \%)$

Not sure

Yes

$8(7 \%)$

$11(8 \%)$

$38(35 \%) \quad 39(30 \%)$

0.72

How often do you look at precautionary food labels?

Only when I buy a product for the first time

Only occasionally when I buy a product

Most of the times when I buy a product

$33(30 \%) \quad 44(34 \%)$

$10(9 \%) \quad 14(11 \%)$

Every time I buy a product

$31(28 \%) \quad 34(26 \%)$

$36(33 \%) \quad 38(29 \%)$

* Calculated using the Pearson $\chi^{2}$ test.

\section{Difference in knowledge between parents of children with and without a past history of anaphylaxis}

There were no differences between the parents of children with and without a past history of anaphylaxis in reading

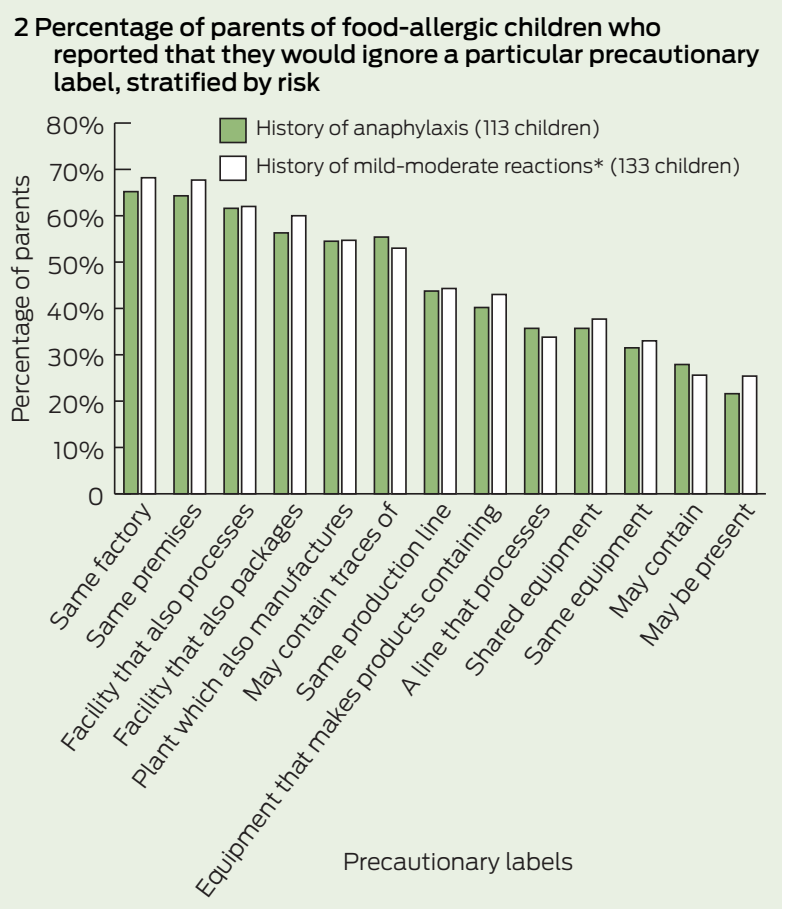

* Vomiting, abdominal pain, diarrhoea, hives, and swelling of the eyes, lips or face. of food labels or whether they would give their child a product if the food they were allergic to was listed in the precautionary labelling section (Box 1). However, parents of children with a past history of anaphylaxis were more likely to remove from the house any food products containing the food to which their child was allergic (Box 1).

\section{Perception, opinions and behaviour relating to precautionary food labels}

In total, the parents of 54 children (48\%) with a history of anaphylaxis felt that the ingredient list information of food labels was easy to understand and use and six (5.4\%) felt that they could trust food labels (Appendix 1 ; online at mja.com.au). The parents of 88 and 106 children with a history of anaphylaxis (78\% and $84 \%$, respectively) thought precautionary labels were not useful and that they did not know whether the food was safe to eat irrespective of the wording of the labels (Appendix 2; online at mja.com. $\mathrm{au}$ ). The vast majority of parents of food-allergic children felt that there should be better government regulation imposed on manufacturers in the way that they use precautionary labels (Appendix 1).
Avoidance of foods by type of precautionary labelling

The proportion of participants with children with a history of anaphylaxis who would avoid feeding the child a particular food product with a precautionary label varied depending on the wording of the precautionary label, with 74 parents $(65 \%)$ reporting that they would ignore the statement "made in the same factory" compared with 24 (22\%) reporting that they would ignore the statement "may be present" (Box 2). However, 68 (60\%) would allow their child to consume foods labelled with this statement if their doctor said it was safe to do so (Appendix 1).

There was no significant difference between parents of children with a history of anaphylaxis compared with those with mild to moderate reactions who reported that they would allow their child to consume foods with precautionary labelling (Pearson $\chi^{2}$ test; Box 1).

There was no difference in parents' self-reported behaviours according to whether or not their child had a history of anaphylaxis (Box 2). However, the precautionary statement "may be present" was perceived as less useful by participants with a child with a history of anaphylaxis compared with a child without a history of anaphylaxis (53 [47\%] v 109 [82\%]: $P<0.05$; Appendix 1).

\section{Discussion}

Our results show that parents of foodallergic children, including those with a child with a past history of anaphylaxis who might be considered to be at greater risk of an adverse reaction, appear complacent about precautionary labelling. In addition, we found that parents of food-allergic children are assuming a gradient level of risk based on the wording of the precautionary statements; this has also been seen previously. ${ }^{2}$ It is also of interest that the VITAL statement "may be present" was seen as most useful, and was taken more seriously despite there being no training or education provided to the participants about the VITAL process.

Our results may be at least partly explained by the ubiquitous nature of precautionary labelling in Australia, 
where more than $65 \%$ of all edible packaged foodstuffs have some form of precautionary labelling. ${ }^{1}$

Similar to our findings, two previous studies reported that patients with allergies were taking risks by disregarding some forms of advisory labelling because they were incorrectly assuming that statements such as "shared facility" and "may contain" indicated different levels of risk. ${ }^{2,6}$ In fact, detectable peanut residues were more common in products that had "shared facility" as a precautionary statement compared with those with a "may contain" statement. ${ }^{6}$ However, previous studies that have investigated consumers' perceptions of precautionary labelling did not stratify people with allergies by the severity of their reaction as we did in this study. 7,8

The key strengths of our study are the response rate of $93 \%$ and the fact that parents of all children attending for a skin-prick test were asked to participate in the study. A possible limitation is that we relied on parents' self-report that their child had medically diagnosed food allergy and a past history of anaphylaxis. However, we believe this is appropriate for this type of study as parents' perceptions and attitudes are likely to drive their choices when making decisions on behalf of their children. Our high participation rate makes a bias towards participation of more anxious families in the study unlikely; however, our results are not necessarily representative of the wider community, as all participants were recruited from a single hospital-based allergy clinic. Furthermore, this study pertains to parent choice for food-allergic children as opposed to older food-allergic patients making decisions for themselves.

In conclusion, the attitudes of parents of food-allergic children to precautionary labelling appear to be complacent, whether or not children had a past history of anaphylaxis. Policies that promote the use of fewer precautionary statements or more effective labelling strategies may lead to less consumer complacency.

Acknowledgements: Giovanni Zurzolo is a PhD student and is funded by Victoria University. Katrina Allen is a Charles and Sylvia Viertel Senior Medical Research Fellow. Jennifer Koplin is supported by a National Health and Medical Research Council Capacity Building Grant in Population Health postdoctoral fellowship. The Murdoch Childrens Research Institute is supported by funding from the Victorian Government's Operational Infrastructure Support Program.

Competing interests: No relevant disclosures.

Received 14 Nov 2012, accepted 6 May 2013.

1 Zurzolo GA, Mathai ML, Koplin J, Allen KJ. Precautionary allergen labelling following new labelling practice in Australia. J Paediatr Child Health 2013; 49: E306-E310.

2 Noimark L, Gardner J, Warner JO. Parents' attitudes when purchasing products for children with nut allergy: a UK perspective. Pediatr Allergy Immunol 2009; 20: 500-504.

3 Taylor SL, Hefle SL. Food allergen labeling in the USA and Europe. Curr Opin Allergy Clin Immunol 2006; 6: 186-190.

4 Allergen Bureau. VITAL O \& A for consumers. 2009. http://www.allergenbureau.net/vital/ vital-qaas (accessed Mar 2013).

5 Sampson HA, Muñoz-Furlong A, Campbell $\mathrm{RL}$, et al. Second symposium on the definition and management of anaphylaxis: summary report-second National Institute of Allergy and Infectious Disease/Food Allergy and Anaphylaxis Network symposium. Ann Emerg Med 2006; 47: 373-380.

6 Hefle SL, Furlong TJ, Niemann L, et al. Consumer attitudes and risks associated with packaged foods having advisory labeling regarding the presence of peanuts. J Allergy Clin Immunol 2007; 120: 171-176.

7 Barnett J, Leftwich J, Muncer K, et al. How do peanut and nut-allergic consumers use information on the packaging to avoid allergens? Allergy 2011; 66: 969-978.

8 Sheth SS, Waserman S, Kagan R, et al. Role of food labels in accidental exposures in foodallergic individuals in Canada. Ann Allergy Asthma Immunol 2010; 104: 60-65.

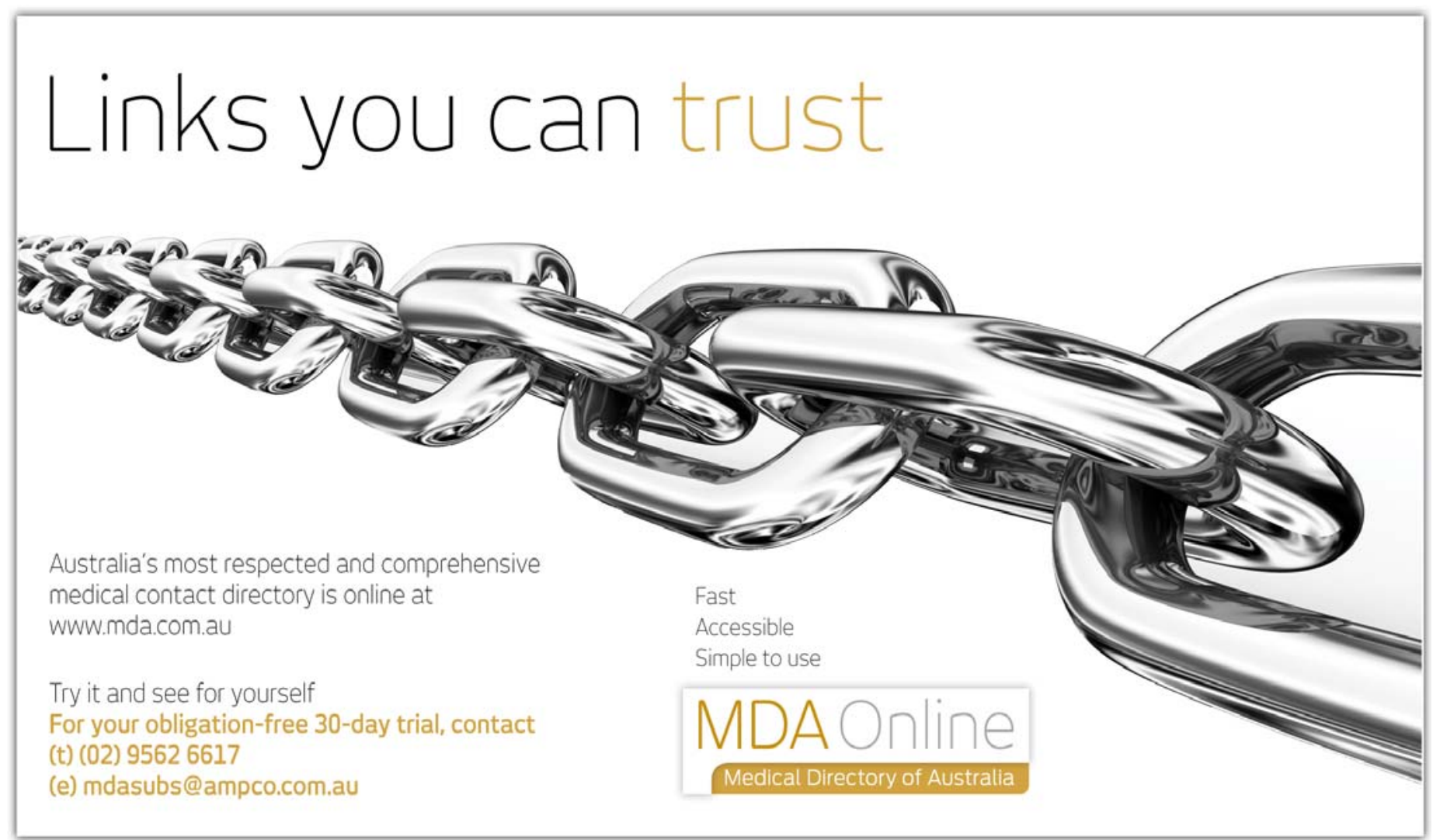

